\title{
EDITORIAL
}

\section{¿Y ahora qué?}

Nuestro país está cambiando y desafortunadamente muchos no se han dado cuenta.

La perestroika (cambio) y el glasnot (transparencia), aceleraron la aparición de otra visión para caminar sobre el planeta. Para algunos ilusos, tradicionalistas, ese movimiento sólo duró hasta la Caída del Muro de Berlín. Sin embargo eso sólo fue el principio.

En nuestro país, la Constitución del 91, fue una traducción a nuestra manera de la Perestroika. Aparecieron conceptos tales como la revocatoria del mandato y la descentralización, formando tenues luces para la democracia criolla.

FECOLSOG ahora, SCOG mañana, están dando los primeros pasos cambiantes y descentralizadores, siguiendo la nueva realidad, reformando sus estatutos y abriéndose a nuevas visiones, colombianas todas ellas, tratando de tomar parte activa en las decisiones de salud gubernamentales, en la educación médica de la especialidad y en los problemas gremiales con la convicción de que el cambio se generará de la periferia hacia el centro, del poder local al nacional, invirtiendo lo que hasta ahora eran dogmas indiscutibles. El centralismo no tiene futuro, fracasó y no va más.

Las Sociedades de Obstetricia y Ginecología de Cartagena y Barranquilla empezaron a dar el tono, los todopoderosos de la medicina prepagada no lo eran tanto. Es sólo el inicio, ¿por qué no imitarlos?

En este orden de ideas se necesitan instituciones médicas modernas, las cuales canalizan las nuevas fuerzas emergentes. Dichas Instituciones, llámese Colegio Médico Nacional por ejemplo, se integrarán de abajo hacia arriba, de afuera hacia adentro, de lo pequeño a lo grande y cuya labor fundamental será la de revocar los mandatos de instituciones e ideas caducas. A éstas últimas les damos las gracias por habernos conducido hasta ahora a través de Academias, Colegios Médicos, Asmedas, etc. Su vigencia ha terminado, vivieron épocas difíciles y perdieron, los absolvemos, hicieron lo que pudieron. Fueron importantes para épocas pretéritas, no para la actual.

Ahora nos corresponde tomar otros rumbos, acordes con los veloces cambios de nuestra época con relatividad y cuántica incluidas. La Gineco-obstetricia colombiana, dispone de figuras jóvenes, excepcionalmente dotadas para liderar movimientos que nos conduzcan al sitio que merecemos. Nada más pero tampoco nada menos. 